\title{
Assessment of the methods available for testing sensation in leprosy patients in a rural setting
}

\author{
B. M. OWEN \& C. J. STRATFORD \\ The Medical School, University of Newcastle upon Tyne NE2 $4 H \mathrm{H}$
}

\author{
Accepted for publication 3 June 1994
}

\begin{abstract}
Summary The aim of this study was to assess the efficacy, practicality and patient understanding of 5 methods used for testing sensation in leprosy patients, in a rural setting. The tests used were the WHO test, cottonwool, pin-prick, monofilaments and the biothesiometer. We concentrated on testing sensation in the hands, and the various tests were carried out on 75 patients and 32 controls, all taken from villagers living at Kindwitwi Leprosy Village, Tanzania. Our results showed that although the WHO test, cottonwool and pin-prick were all easy to use, cheap and well accepted they were not sensitive enough to be of any practical value. We found that the monofilaments, as well as being cheap and easy to use, had great potential value, as the 2-g monofilament could be used as a threshold value (indicative of leprosy, but not diagnostic) for protective sensation with a combined false-positive and false-negative value of only $4 \%$. Finally, the biothesiometer was found to be a precise test that can accurately identify leprosy patients from controls and identify patients at risk of ulceration. It was, however, associated with its own problems, chiefly those of expense and its need of electricity, although we found this latter problem could be easily and relatively cheaply solved by the use of a solar powered recharger (Appendix).
\end{abstract}

\section{Introduction}

Leprosy is feared mainly because of the unsightly deformities and crippling disabilities that may follow. The real goal of leprosy programmes all over the world is to prevent deformities and disabilities caused by leprosy, by arresting the spread of the disease. ${ }^{1}$ One of the most important factors in the prevention of disability is careful monitoring even after completion of treatment. As 'antileprosy' treatment does not necessarily prevent disability, it is essential to follow-up patients at high risk, and most in need of special attention, to prevent the development of disability.

The severe disability and disfigurement resulting from the destruction of tissue is exacerbated by the involvement of nerves. ${ }^{2}$ Sensory testing has been shown to be much more reproducible, and therefore a more reliable method of testing for nerve damage than voluntary muscle testing alone, ${ }^{3}$ although in an ideal situation both would be used. The testing of motor nerve conduction velocity requires capital investment and hospital 
conditions and is therefore not applicable everywhere. ${ }^{4}$ Due to the problems associated with the other forms of testing, testing sensation is probably the best way of detecting nerve damage in rural clinics and the field. Therefore this study deals only with sensory testing. The aim is to assess the efficacy and practicality of the various methods available for testing sensation in the field.

The efficacy of the tests will be assessed by looking at their ability to identify a threshold value indicative of neural involvement and a level of protective sensation. This is a level of sensory loss beyond which patients are at a high risk of developing ulcers and thus becoming disabled. This is important as pressures on money and time make it essential for health workers to identify quickly those patients at the greatest risk of disability.

The various practical values and the problems associated with each test will also be assessed, looking particularly at their expense, requirements, e.g. electricity and special training, and their availability. Also the ease with which patients understood the tests and their acceptance or reluctance to participate in them will be investigated.

The tests selected for this study are the WHO sensory test (using a ball-point pen), cottonwool, pin-prick, monofilaments and the biothesiometer. The first 3 of these tests are all widely used in the Third World. Monofilaments, although widely used in the USA, have only been used in a few areas in the developing world. The biothesiometer has been used in the USA for at least 55 years, ${ }^{5}$ however, its use in the UK has been limited to the last 10-12 years. It was designed to measure the threshold amplitude at which vibration becomes perceptible, and to measure any rise in the threshold during the disease, demonstrating a loss of vibratory sensation, e.g. as in diabetic peripheral neuropathy. ${ }^{6}$

\section{Method}

This study concentrates on testing the sensation in the hands rather than the foot, as there is less person-to-person variation in skin consistancy of the hands. This similarity between subjects is preferable when comparing different testing methods. In assessing the sensitivity of each test, sensation in the ulnar and median nerves in a group of 32 controls, 38 leprosy patients without hand ulcers and 37 leprosy patients with ulcers was recorded. These were then compared and questions were addressed as to whether threshold values, indicative of neural involvement, and a significant and critical loss of protective sensation could be found for each of the tests. The reproducibility of the test was assessed by testing each site 3 times and looking at the variation in values recorded.

\section{SAMPLE OF PATIENTS AND CONTROLS}

The patients and controls used in this study were all villagers at Kindwitwi Leprosy Village, Tanzania. The study was carried out in July and August, which was during the dry season. This is a village of around 600 people, about half of whom have leprosy. Within the village there is a wide range of disability, ranging from many patients with no visible signs of leprosy to others who have lost limbs due to chronic ulceration and infection. There were also 3 patients who did not live in Kindwitwi but came from the Rufiji delta and were identified as leprosy patients at outreach programmes. 
The leprosy patients were divided into 2 groups, those who had never suffered from hand ulcers and those who were at present suffering from hand ulcers. Patients who had a past history of ulceration but without ulcers at the time of the study were excluded.

SUMMARY OF THE TESTS AND HOW THEY WERE USED

In order to try and minimize false results, testing with all the methods was carried out using the following guidelines and principles:

the tests were carried out in a private and quiet room and using an interpreter; no testing session lasted more than 20 mins, as patients can lose interest; a preliminary test was carried out, so the patient understood the test; and after the preliminary test the patient was blindfolded and the selected areas were tested, each area being tested 3 times (a response to all 3 of the stimuli was regarded as 'having sensation'). To maintain concentration in a patient unable to feel at the test sites, areas where sensation was normal (not necessarily test sites) were stimulated after every 4 or 5 unfelt stimuli.

The tests were carried out with the arm and hand relaxed, supinated and fully supported. In order to test the ulnar and median nerve 2 sites were used; distal pulp of the little finger (ulnar nerve) and the distal pulp of the index finger (median nerve). The tests were always carried out in the same order.

\section{WHO sensory test}

This involves the application of firm pressure (sufficient to cause a 2-mm skin indentation) 'vith a ball-point pen on to an area to be tested with the patient blindfolded (all the tests were carried out with the patients blindfolded to minimalize bias). The patient was asked to point to where he felt the pen, and if he was within $2 \mathrm{~cm}$ in both tested areas the test was recorded as positive. If he was unable to do so in 1 or both areas the test was concluded to be negative.

\section{Cottonwool test}

The patient was touched lightly (not stroked across the skin) with a piece of cottonwool rolled into a point. The patient was asked to identify the site touched. It was repeated 3 times at each site and the result for the hand was either positive or negative.

\section{Pin-prick test}

The pin used was sterile and not too sharp. The point was lightly touched on the skin; the test must not cause bleeding. If the individual felt the stimulus, he stated if it was sharp or blunt when compared with the sensation evoked in the normally sensitive skin on the arm.

\section{Monofilaments}

The monofilaments are a set of 4 graded nylon threads, that are calibrated to bend slightly when forces of $0.5 \mathrm{~g}, 2 \mathrm{~g}, 5 \mathrm{~g}$ and $10 \mathrm{~g}$, respectively, are applied to them. The 
threads are individually touched in ascending order, until they bend slightly, and then withdrawn on the skin at the test site. The patient is asked to point to where he felt the stimulus; for obvious reasons the sites should be varied, so nontest sites on the hand are also used. The value that a patient can reliably detect 3 times, at each site is then recorded. The lowest appreciated threshold was recorded as the hand threshold.

\section{Biothesiometer}

The biothesiometer has a handheld plastic probe which is held firmly on the skin. It vibrates at $120 \mathrm{~Hz}$, and is powered by a rechargeable battery. The amplitude at which the probe vibrates can be altered within a range of $0-25 \mu \mathrm{m}$, by varying the voltage (the amplitude being proportional to the square of the voltage). As a preliminary each patient was familiarized with the sensation by turning the amplitude to a maximum. The patient was then blindfolded and tests were carried out by gradually increasing the amplitude from 0 until it was felt and the voltage was noted. The mean of the 3 values for each test site was then calculated and recorded.

\section{Results}

The monofilaments of the stated specifications were unable to demonstrate a clear threshold value, although the 2-g monofilament gave a level of protective sensation. If this level were to be used in a screening test it would be associated with a combined falsepositive and false-negative level of only $4 \%$ (Table 1 ).

It can be seen that all the tests used could only differentiate between a positive and negative result, rather than having a spectrum of graded results, and were not sensitive enough to differentiate any sensory difference between the control group and the group with leprosy (Table 2). Only the cottonwool test produced results that suggested that it could be used as a field test to detect patients at risk of ulceration.

The biothesiometer results demonstrated clear differences between the 3 groups (Figure 1), allowing both threshold and protective sensation values to be identified. Using the value of $4 \mathrm{mV}$ as a threshold value, the results show statistically significant differences between the control group and the leprosy patients (using the $\chi^{2}$-test, $p<0.0005)$. If this value was to be used as a screening level the results would suggest that it would be associated with a combined false-positive, false-negative rate of less than $8 \%$ (Table 3 ).

If the results are further broken down looking at leprosy patients with ulcers and those without it can be seen (Table 4) that if the $10 \mathrm{mV}$ value is used there is again a

Table 1. The distribution of hand thresholds across the 3 groups

\begin{tabular}{lrrrrr}
\hline Group classification & $0 \cdot 5 \mathrm{~g}$ & $2 \mathrm{~g}$ & $5 \mathrm{~g}$ & $10 \mathrm{~g}$ & Negative \\
\hline Control $(n=64)$ & 62 & 2 & 0 & 0 & 0 \\
Leprosy +, ulcer - & 50 & 22 & 4 & 0 & 0 \\
Leprosy +, ulcer + & 0 & 2 & 16 & 12 & 44 \\
\hline
\end{tabular}


Table 2. Number of hands responding to the WHO, cottonwool and pin-prick tests

\begin{tabular}{lcccccr}
\hline Group classification & $\begin{array}{c}\text { WHO } \\
+ \text { ve }\end{array}$ & $\begin{array}{c}\text { WHO } \\
- \text { ve }\end{array}$ & $\begin{array}{c}\text { Wool } \\
+ \text { ve }\end{array}$ & $\begin{array}{c}\text { Wool } \\
\text {-ve }\end{array}$ & $\begin{array}{r}\text { Pin } \\
+ \text { ve }\end{array}$ & $\begin{array}{r}\text { Pin } \\
\text {-ve }\end{array}$ \\
\hline Control $(n=64)$ & 64 & 0 & 64 & 0 & 64 & 0 \\
Lep+ ulcer- $(n=76)$ & 76 & 0 & 72 & 4 & 54 & 22 \\
Lep+, ulcer- $(n=74)$ & 44 & 30 & 6 & 68 & 22 & 52 \\
\hline
\end{tabular}

significant difference (using the $\chi^{2}$-test, $p<0.0005$ ). Using this level as a screening value for protective sensation there would be an associated combined false-positive, falsenegative level of approximately $8 \cdot 5 \%$.

\section{Discussion}

This study set out to assess the efficacy, practicality and the patients' understanding of 5 different methods of sensory testing. Our results agreed with previous studies, ${ }^{4}$ in finding that although the WHO test is cheap, requires no specialized equipment and is easily understood, as it is not a graded test it is of little practical value. Similarly the cottonwool test requires little equipment and is easy to understand; however, it is again limited in not having a graded response. This limitation could explain why although it was able to identify a protective sensation level, it was unable to identify a threshold value. In addition this test is assessing fine touch and it is agreed that it is loss of firm touch that is of prime importance from the point of view of protection, and determines the likelihood of suffering injury. When testing the ability of patients to distinguish between a sharp

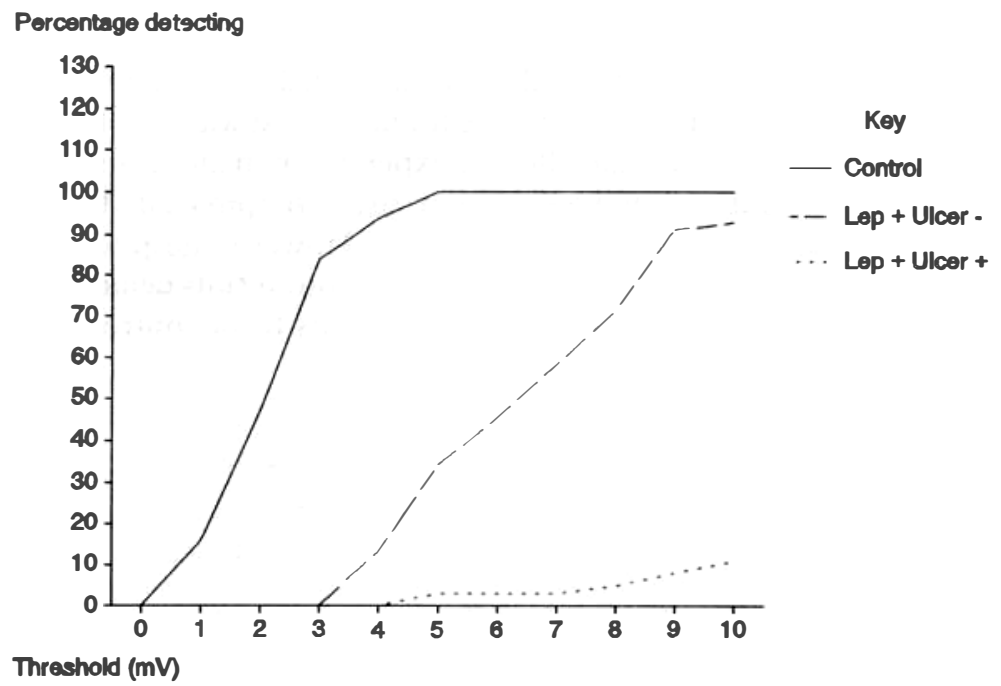

Figure 1. Distribution of vibration thresholds in the 3 groups. 
Table 3. Threshold value detecting leprosy patients

\begin{tabular}{lcc}
\hline Group & Felt 4 & Could not feel \\
\hline Control $(n=64)$ & 56 & 8 \\
Leprosy patients* & 9 & 139 \\
\hline
\end{tabular}

* Two patients did not understand.

and blunt stimulus, there were no difficulties in understanding. However, we feel this test is of limited value for 2 reasons. First it is essential that the needle used in the test is sterile, ${ }^{7}$ unless a sliding pin is used which cannot puncture the skin. ${ }^{2}$ Second, our results demonstrate that it is insufficiently specific to be of any value.

Monofilaments are a specialized piece of equipment. They are, however, inexpensive ( $£ 12$ for a set of 3 ), ${ }^{8}$ and it is also possible to make and calibrate them locally, ${ }^{2,7}$ which is obviously much cheaper. The test can be carried out by any health worker after training for only $10 \mathrm{~min}$ and it is very easy for the patient to understand. We found it to be reproducible and rapid, taking less than $1 \mathrm{~min}$ to complete. Our results illustrated the practical importance of the monofilaments, as the 2-g monofilament can be used as a threshold value for protective sensation, with a low combined false-positive and falsenegative level of $4 \%$. We felt that the inability to identify a threshold level could be remedied by using more finely divided monofilaments, particularly in the lower range.

The biothesiometer has many practical difficulties. It requires an initial financial outlay of around $£ 400$ and also requires specialized knowledge in order for it to be repaired or maintained. A major problem associated with its use is due to the fact that it is electrical and it will only work for just over $1.5 \mathrm{hr}$ before it needs recharging. In the area where this study was carried out there was no electricity and so in order to recharge the biothesiometer we designed and made a solar recharger. This itself was quite simple to make, requiring only 2 large solar cells and a few basic electrical components. (Details of this are to be found in the Appendix.) The equipment for this, however, would be hard to get hold of in the Third World and so would need to be imported in with the biothesiometer, again increasing expenses. We found the test was easy for health workers to carry out but took a lot of time and effort to explain to patients as in rural areas where there is no electricity, vibration is not a sensation easily comprehended, and occasionally that patients were unable to understand the concept. However, despite these problems it is important not to discard it as a method of testing, as our results demonstrated it to be a precise test that can accurately identify leprosy patients from controls and also which

Table 4. Protective sensation value detecting risk of ulcers

\begin{tabular}{lcc}
\hline Group & Felt 10 or less & Could not feel \\
\hline Lep+, ulcer-* & 70 & 5 \\
Lep+, ulcer+* & 8 & 65 \\
\hline
\end{tabular}

* Two patients did not understand. 
patients are at risk of ulceration. Thus if a biothesiometer and methods of recharging it are available, that area is then in the position to carry out an effective screening programme. It is because of this, that we feel that the biothesiometer has and will have an important role in leprosy screening programmes, and should at the very least be available in reference centres.

\section{Acknowledgments}

We would like to thank Drs Mbega and Kombo and Father Robin Lamburn, MBE, who has now sadly passed away, at Kindwitwi Leprosarium for their help in carrying out this project. We would also like to thank Professor K. G. M. M. Alberti for providing us with equipment and ideas.

We are grateful to grants from LEPRA, St Francis Leprosy Guild and the BMDST.

Our thanks are also due to Professor R. J. W. Rees for his guidance and helpful comments on the manuscript.

\section{References}

${ }^{1}$ Srinivasan H. Wanted - a planned approach disability prevention. Ind J Lepr, 1991; 63(1): 1-4.

2 Palande DD, Bowden REM. Early detection of damage to nerves in leprosy. Lepr Rev, 1992; 63: 60-72.

3 Lewis S. Reproducibility of sensory testing and voluntary muscle testing in evaluating the treatment of acute neuritis in leprosy patients. Lepr Rev, 1983; 54: 23-30.

4 Naafs B, Dagne T. Sensory testing: a sensitive method in the follow-up of nerve involvement. Int J Lepr, 1977; 45: 364-8.

5 Bloom S, Till S, Sonksen P, Smith S. Use of a biothesiometer to measure vibration thresholds and their variation in 519 non-diabetic subjects. $\mathrm{Br}$ Med J, 1984; 288: 1793-5.

${ }^{6}$ Laidlaw RW, Hamilton MA. The thresholds of vibratory sensitivity as demonsted by the pallesthesiometer; study of 60 normal subjects. Bull Neurol Inst NY, 1937; 6: 494-503.

7 Pearson JMH. The evaluation of nerve damage in leprosy. Lepr Rev, 1982; 53: 119-30.

8 Kumar S, Fernando DJS, Veves A, Knowles EA, Young MJ, Boulton AJM. Semmes-Weinstein monofilaments: a simple, effective and inexpensive screening device for identif ying diabetic patients at risk of foot ulceration. Diabetes Research and Clinical Practise, 1991; 13: 63-8. 


\section{Appendix}

In order to recharge the biothesiometer we designed a simple solar powered piece of apparatus that could be used in the field (Figure 2). It consisted of 2 separate $12 \mathrm{~V}$ solar cells, which were placed in series and could therefore work independently of each other, should one of them break. These cells could be connected to the biothesiometer, and it could be completely recharged within $3 \mathrm{hr}$ in bright sunlight. The cells were stored in a purpose-built wooden carrying case for protection. The total cost of the components for this unit was less than $£ 25$.

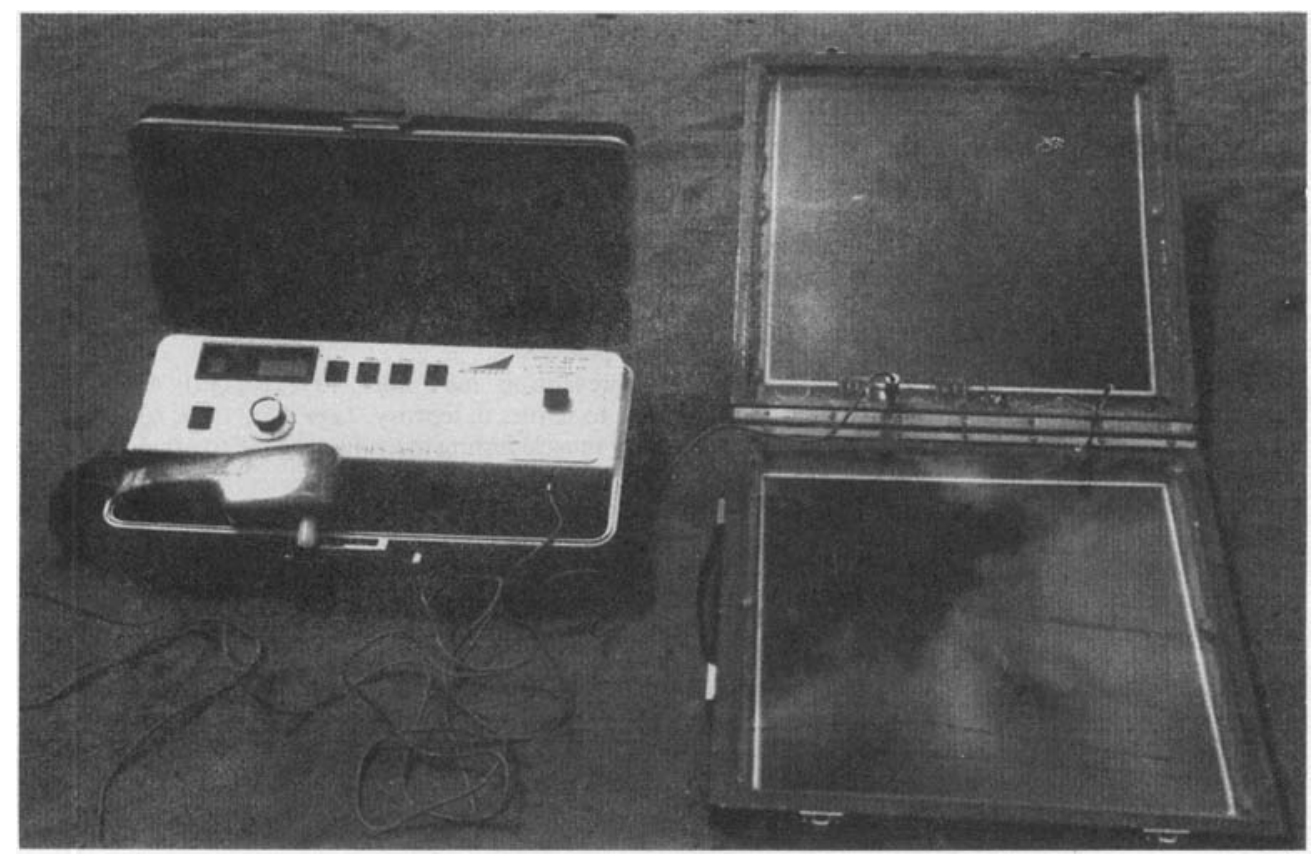

Figure 2. The biothesiometer and its solar recharger. 